\title{
Topical phenylephrine increases anal canal resting pressure in patients with faecal incontinence
}

\author{
M J Cheetham, M A Kamm, R K S Phillips
}

\begin{abstract}
Introduction-The internal anal sphincter receives a stimulatory alpha $a_{1}$ adrenergic innervation. Use of an adrenergic agonist may therefore have a role in treating patients with faecal incontinence.

Methods-Ten patients (seven females, median age 66 years) with passive faecal incontinence related to weak internal anal sphincter were studied. All patients had intact anal sphincters as assessed by endoanal ultrasound. Phenylephrine gel was applied in a double blind manner in concentrations of $0 \%, 10 \%, 20 \%, 30 \%$, and $40 \%$ (Slaco Pharma (UK) Ltd, Watford, UK) on separate days. Maximum resting anal pressure (MRP), anodermal blood flow, blood pressure, and pulse rate were measured before, and one and two hours after application.
\end{abstract}

Results-All concentrations of phenylephrine gel increased median MRP (43, $48,54,65$, and $70 \mathrm{~cm} \mathrm{H}_{2} \mathrm{O}$, for placebo, $10 \% \quad(p=0.122), \quad 20 \% \quad(p=0.170), \quad 30 \%$ $(p=0.002)$, and $40 \% \quad(p=0.004)$, respectively at one hour; comparisons with placebo). This was sustained at two hours. There was a clear dose-response relationship at one hour. Higher concentrations raised median MRP to within the normal range $\left(>60 \mathrm{~cm} \mathrm{H}_{2} \mathrm{O}\right)$. At two hours, all concentrations greater than $20 \%$ increased the pressure to a similar degree, suggesting that the exact concentration may be important for the initial effect but given a certain threshold is less important after a period of time. Toxicity was rare. Two patients experienced transient perianal burning which settled within a few minutes. There was no significant effect on anodermal blood flow, blood pressure, or pulse rate.

Conclusion-This study has demonstrated the feasibility of using topical phenylpatients with faecal incontinence. Randomised controlled trials are required to assess the efficacy of this agent. (Gut 2001;48:356-359)

London, UK

M J Cheetham

M A Kamm

R K S Phillips

Correspondence to: Professor M A Kamm, St Mark's Hospital, Watford Road, Harrow, Middlesex HA 1 3UJ, UK.

kamm@ic.ac.uk

Accepted for publication 3 October 2000 Faecal incontinence is often related to structural sphincter damage, such as obstetric trauma, ${ }^{1}$ accidental trauma, or following anorectal surgery. Incontinence can also occur when the anal sphincter muscles are structurally intact, as assessed by endoanal ultrasound. ephrine to raise resting anal tone in

The commonest cause for this appears to be a degenerative disorder of the internal anal sphincter. $^{2}$ In this condition the internal sphincter becomes fibrotic and weak, leading to a reduced maximum anal canal resting pressure (MRP) and episodes of passive faecal incontinence (loss of stool without the patients's awareness. ${ }^{3}$ )

In minor degrees of faecal incontinence, the use of a pad or anal plug ${ }^{4}$ may ease symptoms. The use of loperamide and low fibre diet may also be appropriate. In patients with external anal sphincter disruption, surgical repair of the sphincter is effective. ${ }^{5}$ In severe cases, major reconstructive surgery, such as an artificial sphincter implant ${ }^{6}$ or graciloplasty, ${ }^{7}$ may merit consideration. Such procedures are however still in the development phase and carry a high rate of complications and reoperation. Many patients have relatively minor symptoms which do not merit such radical surgery.

The internal anal sphincter exists in a state of tonic contraction, and is the main factor responsible for the generation of anal canal resting pressure. ${ }^{8}$ Given that the internal anal sphincter receives an extrinsic innervation which modulates its tone, we hypothesised that it may be possible to mimic the effect of this innervation and pharmacologically increase internal anal sphincter tone.

Phenylephrine is a selective alpha ${ }_{1}$ agonist which causes internal sphincter contraction in vitro $^{910}$ and elevates MRP in animal studies. ${ }^{11}$ A recent pilot study from this unit has shown that topical phenylephrine can increase internal anal sphincter tone in healthy volunteers. ${ }^{12}$ This dose ranging study demonstrated that $10 \%$ phenylephrine gel was the optimum concentration, raising MRP by a mean of $33 \%$. This elevation in MRP persisted for a median of seven hours following a single application. However, when the efficacy of $10 \%$ phenylephrine in treating faecal incontinence was assessed in a controlled trial, the clinical response was disappointing. ${ }^{13}$ Of 36 patients enrolled in the study, six reported a significant improvement in their symptoms. Patients with faecal incontinence are known to have an internal anal sphincter which is less responsive to alpha adrenoceptor agonists in vitro. ${ }^{14}$ The poor in vivo response may therefore have been related to an inadequate concentration of the applied gel.

This study therefore aimed to assess the effect of topical phenylephrine on MRP in patients with passive faecal incontinence and to determine its optimal concentration.

Abbreviations used in this paper: MRP, maximum anal resting pressure. 
Table 1 Effect of a single application of a gel containing different phenylephrine concentrations on maximum anal resting pressure (MRP)

\begin{tabular}{llllll}
\hline $\begin{array}{l}\text { Phenylephrine } \\
\text { concn }\end{array}$ & Baseline MRP & MRP at 1 $h$ & $p^{*}$ & MRP at 2 $h$ & $p^{*}$ \\
\hline Placebo & $35.5(29-68)$ & $42.5(31-64)$ & N/A & $48.0(30-58)$ & N/A \\
$10 \%$ & $35.5(19-77)$ & $48.0(28-82)$ & 0.122 & $63.5(32-76)$ & 0.068 \\
$20 \%$ & $38.0(29-60)$ & $54.0(33-81)$ & 0.170 & $56.0(30-80)$ & 0.224 \\
$30 \%$ & $37.0(28-68)$ & $65.0(32-77)$ & 0.002 & $67.5(29-80)$ & 0.002 \\
$40 \%$ & $43.0(29-60)$ & $69.5(28-89)$ & 0.004 & $63.5(31-82)$ & 0.006
\end{tabular}

Values are median (range).

Results from 10 patients with passive faecal incontinence. Values at one and two hours were compared with values pretreatment (baseline). Subjects were studied on five separate days.

${ }^{\star}$ Comparison with placebo using Friedman multiple comparisons (Boneferroni corrected value).

\section{Patients and methods}

We studied patients with exclusively passive faecal incontinence - that is, loss of stool without the patient's awareness. All complained of episodes of faecal incontinence to liquid or solid stool.

All patients were assessed by anorectal physiological testing and endoanal ultrasound scanning. ${ }^{15}$ Patients were included only if they had circumferentially intact sphincters demonstrable on endoanal ultrasound scanning, and a low MRP indicative of impaired internal anal sphincter function.

Patients were excluded if they were pregnant, had ischaemic heart disease, aortic aneurysm, uncontrolled hypertension, inflammatory bowel disease, or other disorders known to cause secondary faecal incontinence.

Patients attended for five visits a minimum of 48 hours apart. At the first visit, incontinence scores were assessed for each patient. Continence was rated from 0 (perfect continence) to 24 (daily episodes of incontinence to solid stool with major lifestyle restriction) using a recently published faecal incontinence grading scale. ${ }^{16}$

On each of the five study days, measurements were made of MRP, anodermal blood flow, blood pressure, and pulse rate at baseline (pre-gel application), and at one and two hours after application. When baseline measurements had been obtained, a $2.5 \mathrm{~cm}$ strip of the test gel was applied to the distal anal canal using the gloved index finger of the investigator.

MRP was measured in each subject using an eight channel water perfused anorectal manometry system (Mui Scientific, Ontario, Canada). A station pull through technique was used at $1 \mathrm{~cm}$ intervals to identify the point of MRP. The catheter was then left in situ to establish a stable resting pressure. MRP was determined by taking the mean of the eight circumferential pressure measurements. Anodermal blood flow was measured using the DRT4 laser Doppler flowmeter (Moor Instruments, Devon, UK). The skin probe was applied to the skin of the anus and held until a steady reading was obtained. Anodermal blood flow was calculated by taking the mean of four quadrant readings around the anus.

Gels containing no active ingredient (placebo), and $10 \%, 20 \%, 30 \%$, and $40 \%$ phenylephrine were used. All gels were supplied in identical coded foil tubes by Slaco Pharma (UK) Ltd (Watford, UK). Both the investigator and patients were unaware of the nature of each gel. Gels were applied in a random order defined before the start of the study.
Ethics committee approval for the study was obtained from the Harrow and District Research Ethics Committee. Informed consent was obtained from each patient prior to the study.

STATISTICAL METHODS

Data were analysed using the Shapiro-Wilk test to assess for normal distribution. As data were not normally distributed, further analysis was performed using non-parametric tests. The Wilcoxon signed ranks test was used to compare data at one and two hours with baseline data. The Friedman test (non-parametric analysis of variance) was used to assess the difference in anal pressure between each treatment and placebo, at both one and two hours. As multiple analyses were performed for each concentration, the Bonferroni correction was performed for each $\mathrm{p}$ value. A corrected $\mathrm{p}$ value of less than 0.05 was considered statistically significant. Data were unblinded following analysis.

\section{Results}

PATIENTS

Ten patients (three males) with a median duration of incontinence of two years (range 1-7) were studied. Median incontinence score was 13.5 (range $7-20$ out of 24).

Endoanal ultrasound demonstrated the integrity of both anal sphincters in all patients. The mean thickness of the internal anal sphincter was $1.9 \mathrm{~mm}$ (range 1.1-2.7). At the time of patient selection, anorectal physiological testing demonstrated a median MRP of $38.5 \mathrm{~cm} \mathrm{H}_{2} \mathrm{O}$ (range 13-60, normal in our laboratory $>60 \quad \mathrm{~cm} \mathrm{H}_{2} \mathrm{O}$ ), with a median squeeze pressure of $100 \mathrm{~cm} \mathrm{H}_{2} \mathrm{O}$ (range 51-288, normal $>60 \mathrm{~cm} \mathrm{H}_{2} \mathrm{O}$ ). Median left pudendal nerve terminal motor latency was 2.1 (range 1.3-2.2). Median right pudendal nerve terminal motor latency was 2.2 (range 1.62.2).

EFFECT ON MAXIMUM RESTING PRESSURE

There was no significant difference between baseline MRPs for the five study days when the placebo and four different concentrations were tested. Application of all concentrations of phenylephrine gels resulted in an increase in median MRP at both time points (table 1). This effect was statistically significant $(p<0.05$ compared with placebo) at both one and two hours for phenylephrine gels in concentrations of $30 \%$ and $40 \%$ only. Application of $30 \%$ and $40 \%$ phenylephrine resulted in an increase in median MRPs to within the normal range for this unit $\left(60-120 \mathrm{~cm} \mathrm{H}_{2} \mathrm{O}\right)$. Individual patient data are shown in figs $1-3$. Three patients had minimal response to all concentrations of phenylephrine studied (defined as an elevation less than $10 \mathrm{~cm} \mathrm{H}_{2} \mathrm{O}$ in maximum resting pressure at either time point) (figs 1-3).

EFFECT ON SKIN FLUX

There was wide variation in values obtained for anodermal skin flux, both within and between patients. No significant effect on skin flux was 


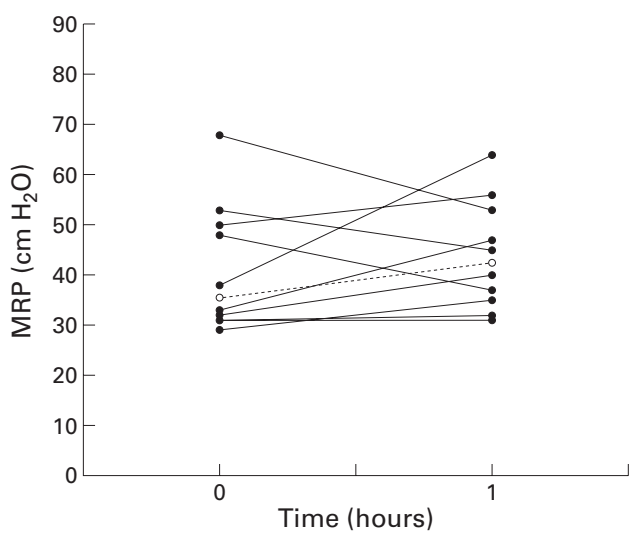

Figure 1 Effect of a single application of placebo gel on maximum anal resting pressure (MRP) in 10 patients with faecal incontinence, measured prior to application and one hour after application (broken line indicates median values)

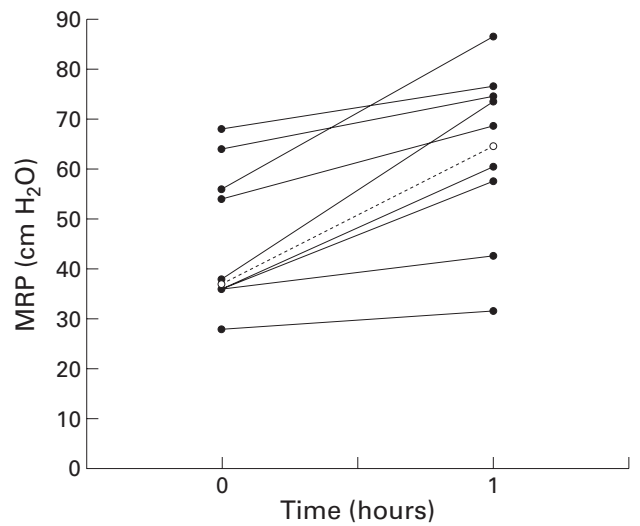

Figure 2 Effect of a single application of $30 \%$ phenylephrine gel on maximum anal resting pressure (MRP) in 10 patients with faecal incontinence, measured prior to application and one hour after application (broken line indicates median values)

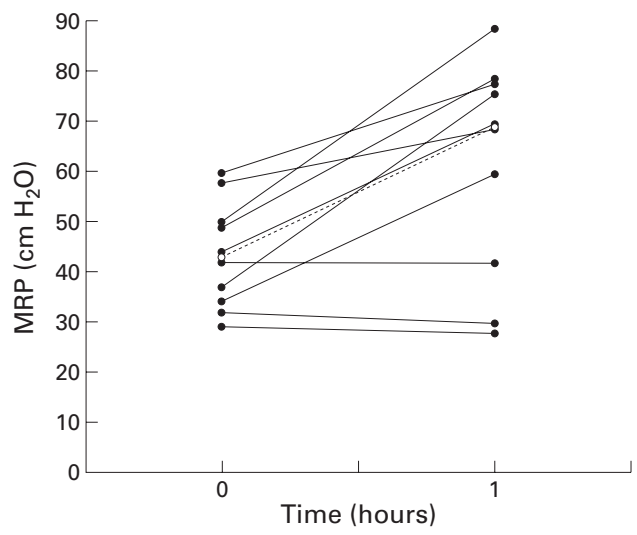

Figure 3 Effect of a single application of $40 \%$ phenylephrine gel on maximum anal resting pressure (MRP) in 10 patients with faecal incontinence, measured prior to application and one hour after application (broken line indicates median values)

noted with any of the concentrations of phenylephrine studied.

EFFECT ON THE CARDIOVASCULAR SYSTEM No significant change was observed in either pulse rate or diastolic blood pressure for all concentrations of phenylephrine.
LOCAL SIDE EFFECTS

One patient reported a stinging sensation immediately on application of $30 \%$ phenylephrine gel. Another patient reported transient burning on application of $20 \%$ and $40 \%$ phenylephrine, but not with other concentrations. In all cases, local discomfort settled within 20 minutes. The remaining eight patients did not report any local side effects on direct questioning. No patient reported a rash.

Three patients who had no response or only a minimal response to phenylephrine were identified (non-responders). There were no clear differences between responders and nonresponders in relation to clinical or investigational parameters. The numbers were too small to compare statistically, given that there were three non-responders and seven responders.

\section{Discussion}

This study has demonstrated that it is possible to increase the resting tone of the internal anal sphincter in patients with faecal incontinence. This has not been demonstrated previously. We have also shown that this is possible using a topical preparation, minimising the potential for systemic side effects. A dose-response relationship was demonstrated, with higher doses causing an increase in resting pressure. With higher doses the increase in resting pressure was of a magnitude which increased the pressure to within the normal range, suggesting that this effect has therapeutic potential.

Minimal toxicity was noted. Phenylephrine has been used topically in ophthalmology with reports of local irritation ${ }^{17}$ and cardiovascular side effects. ${ }^{18}$ However, the cornea may offer greater access to the systemic circulation than the anoderm. In the current study, even with higher concentrations of gel, only minor skin irritation was observed by two patients and this resolved after a few minutes. Longer term studies will need to explore local side effects in greater detail. Anodermal blood flow was not affected, suggesting that the vasoconstrictive effect of phenylephrine was balanced by other local factors. No effect on blood pressure was observed.

Previous work from our unit demonstrated that $10 \%$ topical phenylephrine significantly increased the MRP in healthy volunteers, ${ }^{12}$ and that higher concentrations did not achieve a greater resting pressure. This concentration was then used in a double blind study of patients with an ileoanal pouch and faecal incontinence. ${ }^{19}$ These patients had a structurally normal anal sphincter and a normal resting pressure, with faecal incontinence thought to relate to lack of normal neural sphincter control. Half of the patients achieved clinical benefit, and one third had complete resolution of their incontinence.

However, when this concentration of phenylephrine was used in a double blind trial of patients with faecal incontinence due to a weak but intact sphincter, ${ }^{13}$ benefit was experienced by only a minority of patients, with no significant effect for the group as a whole. This led us to reconsider the nature of the pathology in these patients, and consequently pharmaco- 
logical requirements. In vitro work has shown that the internal anal sphincter in patients with faecal incontinence is less responsive to adrenergic neurotransmitters than muscle from healthy patients, with a shift in the doseresponse curve. ${ }^{14}$ The current study suggests that this is mirrored clinically.

The range of concentrations of gel tested in this study was selected on the basis of practical considerations in relation to formulation, although it was anticipated from the volunteer study $^{12}$ and in vitro work ${ }^{14}$ that a concentration of greater than $40 \%$ was unlikely to be needed. At one hour the different gels produced different increases in sphincter pressure in a dose related manner. At two hours all concentrations seemed to increase the pressure to a similar degree, although the pressure responses obtained with $10 \%$ and $20 \%$ phenylephrine were not significant. This suggests that the exact concentration may be important for the initial effect but given a certain threshold is less important after a period of time. This may relate to the time required for a certain amount of the drug to diffuse through the anoderm and saturate the relevant receptors.

The analysis in this study was performed using comparison with placebo on a different day. Although concentrations of $10 \%$ and $20 \%$ phenylephrine resulted in a modest increase in median resting pressure, this was not statistically significant. In contrast, application of $30 \%$ and $40 \%$ phenylephrine resulted in a significant increase in resting pressure at both time points compared with placebo.

Figures 1-3 demonstrate that three patients with the lowest resting anal pressure had the lowest response to topical therapy, and this low response occurred even with $40 \%$ gel. A subgroup of patients may therefore have marked fibrosis and sphincter weakness, which is unresponsive to therapy. This fibrosis ${ }^{20}$ and lack of pharmacological respons $\mathrm{e}^{14}$ have been observed in vitro.

One hour after application there was a doseresponse relationship for different concentrations. The pressure response was maintained at two hours. Given this two hour response, and data from volunteer studies suggesting that the effect of a single application of topical phenylephrine is sustained for a median of seven hours, ${ }^{12}$ we believe there is the potential for a sustained clinical response.

At inclusion, all patients had an MRP of less than $60 \mathrm{~cm} \mathrm{H}_{2} \mathrm{O}$ (the lower limit of the normal range for this unit). Each patient was studied on several separate occasions. On some of these subsequent occasions, baseline values for MRP were slightly greater than $60 \mathrm{~cm} \mathrm{H}_{2} \mathrm{O}$. This reflects natural variation in measurement. These patients did however have passive faecal incontinence and had a low resting pressure measured on more than one occasion.

This dose ranging study was restricted to patients with a weak sphincter and passive faecal incontinence. This group is likely to need the greatest concentration of phenylephrine to improve sphincter function. It is possible that this type of topical therapy will affect sphincter function even in the presence of structural damage, or when the main complaint is urgency and the sphincters are intact and functioning normally. Phenylephrine causes relaxation of rectal circular muscle in vitro, ${ }^{10}$ and this effect may also contribute to improved continence. An open study in which phenylephrine was administered systemically to volunteers demonstrated no alteration in colonic motility $^{21}$; these studies suggest that accidental rectal administration of topical phenylephrine will not adversely affect the rectoanal pressure gradient. The aim of the present study was restricted to exploring the feasibility of using a topical alpha ${ }_{1}$ agonist to increase anal resting pressure. Further studies may assess the effect of topical phenylephrine on rectal motility.

Clinical studies are now required in patients with faecal incontinence to assess the efficacy of this treatment.

M J Cheetham is funded by the Jack Slagel Foundation.

Conflict of interest. Financial support for the study was received from SLA Pharma.

1 Sultan AH, Kamm MA, Hudson CN, et al. Anal-sphincter disruption during vaginal delivery. $N$ Engl $7 \mathrm{Med}$ disruption during

2 Vaizey CJ, Kamm MA, Bartram CI. Primary degeneration of the internal anal sphincter as a cause of passive faecal incontinence. Lancet 1997;349:612-15.

3 Engel AF, Kamm MA, Bartram CI, et al. Relationship of symptoms in faecal incontinence to specific sphincter abnormalities. Int $\mathcal{F}$ Colorectal Dis 1995;10:152-5.

4 Mortensen N, Humphreys MS. The anal continence plug: a disposable device for patients with anorectal incontinence. Lancet 1991;338:295-7.

5 Engel AF, Kamm MA, Sultan AH, et al. Anterior anal sphincter repair in patients with obstetric trauma. Br F Surg 1994;81:1231-4.

6 Vaizey CJ, Kamm MA, Gold DM, et al. Clinical, physiologi$\mathrm{cal}$, and radiological study of a new purpose-designed artical, and radiological study of a new purpose-d
ficial bowel sphincter. Lancet 1998;352:105-9.

7 Baeten CG, Konsten J, Spaans F, et al. Dynamic graciloplasty for treatment of faecal incontinence. Lancet 1991;338:1163-5.

8 Penninckx F, Lestar B, Kerremans R. The internal anal sphincter: mechanisms of control and its role in maintaining anal continence. Baillieres Clin Gastroenterol 1992;6: 193-214.

9 Regadas FS, Batista LK, Albuquerque JL, et al. Pharmacological study of the internal anal sphincter in patients with chronic anal fissure. Br $\mathcal{A}$ Surg 1993;80:799-801.

10 O'Kelly TJ, Brading A, Mortensen NJ. In vitro response of the human anal canal longitudinal muscle layer to cholinergic and adrenergic stimulation: evidence of sphincter specialization. Br f Surg 1993;80:1337-41.

11 Yamato S, Rattan S. Role of alpha adrenoceptors in opossum internal anal sphincter. F Clin Invest 1990;86:424

12 Carapeti EA, Kamm MA, Evans BK, et al. Topical phenylephrine increases anal sphincter resting pressure. Br F Surg 1999;86:267-70.

3 Carapeti EA, Kamm MA, Phillips RK. Randomized controlled trial of topical phenylephrine in the treatment of faecal incontinence. Br F Surg 2000;87:38-42.

14 Speakman CT, Hoyle CH, Kamm MA, et al. Adrenergic control of the internal anal sphincter is abnormal in patients with idiopathic faecal incontinence. Br f Surg 1990;77:1342-4.

15 Law PJ, Bartram CI. Anal endosonography: technique and normal anatomy. Gastrointest Radiol 1989;14:349-53.

16 Vaizey CJ, Carapeti E, Cahill JA, et al. Prospective comparison of faecal incontinence grading systems. Gut 1999;44 son of

17 Anibarro B, Barranco P, Ojeda JA. Allergic contact blepharoconjunctivitis caused by phenylephrine eyedrops. Contact Dermatitis 1991;25:323-4

18 Fraunfelder FT, Scafidi AF. Possible adverse effects from topical ocular 10\% phenylephrine. Am f Ophthalmol 1978; 85:447-53.

19 Carapeti EA, Kamm MA, Nicholls RJ, et al. Double blind trial demonstrates that topical phenylephrine improves nocturnal incontinence in patients with an ileo-anal pouch. Colorectal disease: Association of Coloproctology, Annual Meeting, Jersey, 1998

20 Speakman CT, Hoyle CH, Kamm MA, et al. Abnormal internal anal sphincter fibrosis and elasticity in fecal incontinence. Dis Colon Rectum 1995;38:407-10.

21 Bharucha AE, Camilleri M, Zinsmeister AR, et al. Adrenergic modulation of human colonic motor and sensory function. Am f Physiol 1997;273(5Pt1):G997-1006. 